\title{
Effect of small and radical surgical injury on the level of different populations of circulating tumor cells in the blood of breast cancer patients
}

\author{
E. V. KAIGORODOVA ${ }^{1,2,3, *}$, N. A. TARABANOVSKAYA ${ }^{1}$, M. N. STAHEEVA ${ }^{1}$, O. E. SAVELIEVA ${ }^{1}$, L. A. TASHIREVA ${ }^{1}$, E. V. DENISOV ${ }^{1,2}$, \\ V. M. PERELMUTER ${ }^{1,3}$
}

${ }^{1}$ Cancer Research Institute, Tomsk National Research Medical Center, Russian Academy of Sciences, 5 Kooperativny Street, Tomsk 634050, Russian Federation; ${ }^{2}$ Laboratory for Translational Cellular and Molecular Biomedicine, Tomsk State University, 36 Lenin Prospekt, Tomsk, 634050, Russian Federation; ${ }^{3}$ Siberian State Medical University, Tomsk 634050, Russian Federation

${ }^{*}$ Correspondence: kaigorodova@oncology.tomsk.ru

Received September 1, 2016 / Accepted November 6, 2016

\begin{abstract}
Circulating tumor cells (CTCs) constitute a heterogeneous population. Some tumor cells are cancer stem cells (CSCs), while others are in the process of the epithelial-mesenchymal transition (EMT); however, most CTCs are neither stem cells nor in the EMT. This prospective study of 22 patients with nonspecific-type invasive carcinoma of the breast identified different populations of CTCs by flow cytometry in the blood of patients before biopsy, after biopsy and after surgical tumor removal without neoadjuvant chemotherapy. The results showed that minor surgical injury (biopsy) was accompanied by a significant increase in the blood levels of CTCs without signs of the EMT or stemness (Epcam+CD45-CD44-CD24Ncadh-) and CTCs with signs of stemness and without signs of the EMT (Epcam+CD45-CD44+CD24-Ncadh-). Our results suggest that minor surgical injury to a tumor contributes to the release of CTCs into the bloodstream, including a population of stem cells.
\end{abstract}

Key words: breast cancer, circulating tumor cells (CTCs), cancer stem cells (CSCs), epithelial-mesenchymal transition (EMT), flow cytometry

Circulating tumor cells (CTCs) constitute a heterogeneous population. Some tumor cells are cancer stem cells (CSCs), while others are in the process of the epithelial-mesenchymal transition (EMT); however, most CTCs are neither stem cells nor in the EMT. There is increasing interest in the study of the molecular biological characteristics of CTCs. In particular, the small population of CSCs shows two important features: the ability to self-renew and to be refractory to chemotherapy and radiation therapy [1-5].

With a higher metastatic potential than other tumor cells, CSCs disseminate to premetastatic niches, initiate the metastatic process and contribute to disease recurrence, even after seemingly successful treatment [6].

In this context, the aim of our study was to identify the different populations of CTCs (CTCs without signs of stemness or the EMT, CTCs with signs of the EMT and without signs of stemness, CSCs without signs of the EMT and CTCs with signs of both stemness and the EMT) in the blood of patients with nonspecific-type invasive carcinoma of the breast before biopsy, after biopsy and after surgical tumor removal without neoadjuvant chemotherapy.

\section{Materials and methods}

Research materials. This prospective study included 22 patients with newly diagnosed invasive breast cancer between the ages of 18 and 50 years and a tumor volume $\geq 2.0 \mathrm{~cm}$ who received treatment at the Cancer Research Institute, Tomsk. The criteria for inclusion in the study were the patient's consent to participate in the study, a morphologically verified diagnosis of invasive carcinoma of the nonspecific type, T2-4N0-3M0, and a generally satisfactory condition $(\leq 2$ on the Eastern Cooperative Oncology Group scale).

The exclusion criteria were other histological types of breast cancer or multiple primary malignant tumors. The material for the study was venous heparinized blood taken prior to biopsy, 3-7 days after biopsy and 3-7 days after surgical tumor removal without neoadjuvant chemotherapy. 
The clinicopathological parameters of the patients with breast cancer are presented in Table 1.

Flow cytometry. Different populations of CTCs were evaluated by flow cytometry using a BD FACSCanto system (Becton, Dickinson and Company (BD), USA) with BD FACSDiva software. For this procedure, stabilized heparin venous blood was incubated with different fluorochrome-labeled monoclonal antibodies to CD45 (clone F10-89-4, PE/Cy7) (Abcam, UK), CD44 (clone IM7, FITC) (Abcam, UK), CD24 (clone SN3, phycoerythrin) (Abcam, UK), EpCAM (clone VU-1D9, PerCP/Cy5.5) (Abcam, UK) and CD325 (N-Cadherin) (clone 8C11, APC) (Biolegend, USA). Then, erythrocytes were lysed in lysis solution (BD FACS lysing solution) and washed twice with CellWash buffer. The cell pellet was resuspended in $1 \mathrm{ml}$ of BD Flow buffer. All samples were stored in the dark at $4^{\circ} \mathrm{C}$ and were analyzed within 1 hour.

The following molecular markers for CTCs were analyzed: EpCAM, CD45, CD44, CD24 and CD325 (N-cadherin). The cells were then classified based on the evidence of the EMT and the presence or absence of stem cell markers (EpCAM+CD45CD44-CD24-Ncadh-; EpCAM+CD45-CD44-CD24-Ncadh+; EpCAM+CD45-CD44+CD24-Ncadh+; EpCAM-CD45CD44+CD24-Ncadh-; EpCAM-CD45-CD44+CD24-Ncadh-; EpCAM-CD45-CD44+CD24-Ncadh+).

The cell results are reported as the proportion of the number of events with respect to CD45 expression multiplied by the concentration of leucocytes in $1 \mathrm{ml}$ of blood. To perform this analysis simultaneously with immunophenotyping, cells were placed in a hematology analyzer to determine the total number of blood leukocytes. The resulting number of test cells was obtained per $\mathrm{ml}$ of blood.

Statistical analysis. The obtained data were processed using variation statistics. Assessment of the normal distribution

Table 1. The clinicopathological parameters of patients with nonspecifictype invasive carcinoma of the breast

\begin{tabular}{lll}
\hline Clinicopathological parameters & & $\mathrm{N}(\%)$ \\
\hline Age (year) (Me (Q1-Q3)) & $49(42-57)$ & $22(100 \%)$ \\
\hline \multirow{3}{*}{ Molecular type of breast cancer } & Luminal A & $3 / 22(13.7 \%)$ \\
& Luminal B1 & $10 / 22(45.5 \%)$ \\
& Luminal B2 & $1 / 22(4.5 \%)$ \\
& HER2-positive & $1 / 22(4.5 \%)$ \\
& Triple-negative & $7 / 22(31.8 \%)$ \\
\hline \multirow{3}{*}{ Tumor size } & T1 & $4 / 22(18.2 \%)$ \\
& T2 & $17 / 22(77.3 \%)$ \\
& T3 & $1 / 22(4.5 \%)$ \\
& T4 & $0(0 \%)$ \\
\hline \multirow{3}{*}{ Lymph node status } & N0 & $10 / 22(45.5 \%)$ \\
& N1 & $7 / 22(31.8 \%)$ \\
& N2 & $4 / 22(18.2 \%)$ \\
Neoadjuvant chemotherapy (NAC) & N3 & $1 / 22(4.5 \%)$ \\
\hline & YES & $8 / 22(36.4 \%)$ \\
& & $14 / 22(63.6 \%)$ \\
\hline
\end{tabular}

of the results was performed using the Kolmogorov-Smirnov test. The significance of differences was assessed using the nonparametric Mann-Whitney test (for independent samples) and the Wilcoxon test (for dependent samples). Data are presented as the median $(\mathrm{Me})$ and the upper and lower quartiles (Q1-Q3). Differences were considered significant at a significance level of $\mathrm{p}<0.05$.

\section{Results}

This prospective study of 22 patients with nonspecific invasive carcinoma of the breast defined various subpopulations of CTCs by flow cytometry in the blood of patients before biopsy, after biopsy and after surgical tumor removal without neoadjuvant chemotherapy. On the basis of the molecular markers EpCAM, CD45, CD44, CD24 and CD325 (N-cadherin), we classified CTCs into populations showing evidence of the EMT and with and without the presence of stem cell markers (Figure 1). Tumor cells are characterized as epithelial cells which are positive, among others, for EpCAM or cytokeratins [7]. Furthermore, distinct CD44+/CD24- and CD133+ subpopulations with CSC characteristics have been detected in breast tumors [8-10]. CD325 (N-Cadherin) is a marker for EMT $[11,12]$.

Cells with the immunophenotype EpCAM+CD45CD44-CD24-Ncadh- were regarded as CTCs without signs of stemness or the EMT; EpCAM+CD45-CD44-CD24$\mathrm{Ncadh}+$ cells were classified as CTCs with signs of the EMT but without signs of stemness; EpCAM+CD45CD 44+CD24-Ncadh-cells were classified as CTCs including stem cells without signs of the EMT; and the cell phenotypes EpCAM+CD45-CD44+CD24-Ncadh+, EpCAM-CD45-CD44+CD24-Ncadh- and EpCAM-CD45CD44+CD24-Ncadh+ were classified as CTCs with signs of both stemness and the EMT.

As a result of these investigations, we discovered that a small surgical trauma (biopsy) was accompanied by a significant increase in the blood levels of CTCs without signs of EMT nor stemness (EpCAM+CD45-CD44-CD24-Ncadh-) and CTCs with signs of stemness (EpCAM+CD45-CD44+CD24Ncadh-). On the other hand, the level of CSCs showing a loss of epithelial markers (EpCAM-CD45-CD44+CD24-Ncadh-) was significantly decreased after biopsy (Table 2).

This study also revealed that 3-7 days after surgical tumor removal, there were no statistically significant increases in the levels of CTCs in the blood of patients with breast cancer (Figure 2).

\section{Discussion}

There has recently been increased interest in studying the mechanisms of dissemination and the molecular and biological characteristics of CTCs. In experimental models, primary tumor cells have been found to disseminate and enter the bloodstream, with numbers ranging from a few thousand up to 
four million cells per gram of tissue [13, 14]. Of all the CTCs, only 1 of 40 cells reaches a premetastatic niche, and no more than $0.01 \%$ of CTCs give rise to metastases [15].

It has been shown that some CSCs can be detected in the blood long after primary tumor removal. For example, cancer cells are often found in the blood of breast cancer patients 5 to 10 or more years after surgery. At the same time, $20 \%$ of women develop disease progression in the period from 7 to
25 years after radical mastectomy [16]. This behavior of tumor cells may be due to the properties of stem cells and the ability to remain "dormant" for a long time and become activated in response to stimuli. Indeed, late metastasis can be seen after the "radical cure" documented in prostate cancer, thyroid cancer, renal carcinoma and melanoma [17].

The presence of CTCs is not always accompanied by the formation of metastases, apparently because not all tumor cells
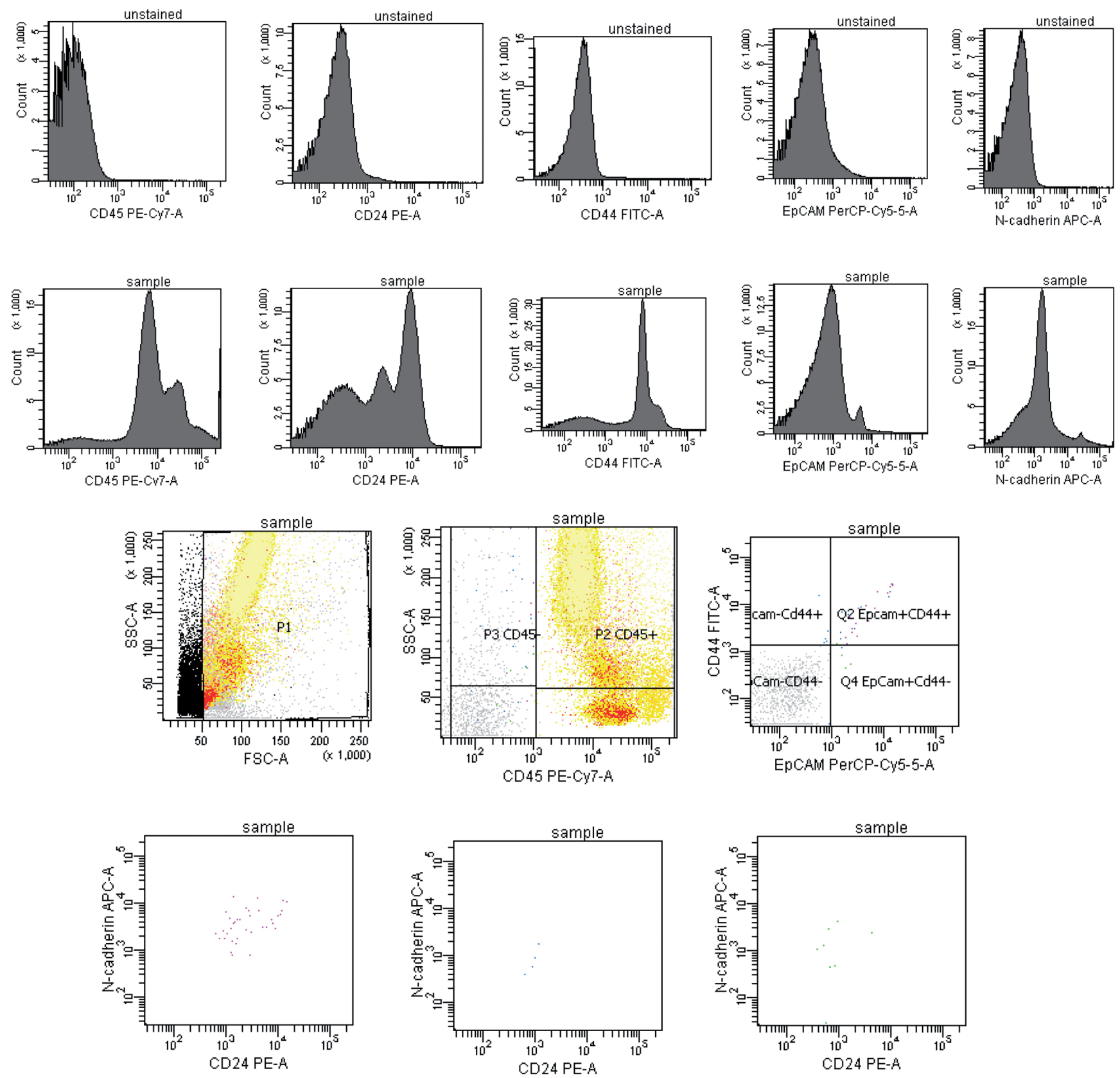

Figure 1. Determination of different populations of CTCs by flow cytometry. Samples were incubated with labeled monoclonal antibodies to CD45, CD44, CD24, EpCAM, and CD325 (N-cadherin). Our gating strategy separated the populations into CD45-negative and CD45-positive cells, and then the expression of EpCAM, CD44, CD24, CD325 was measured among the CD45-negative nucleated cells. 

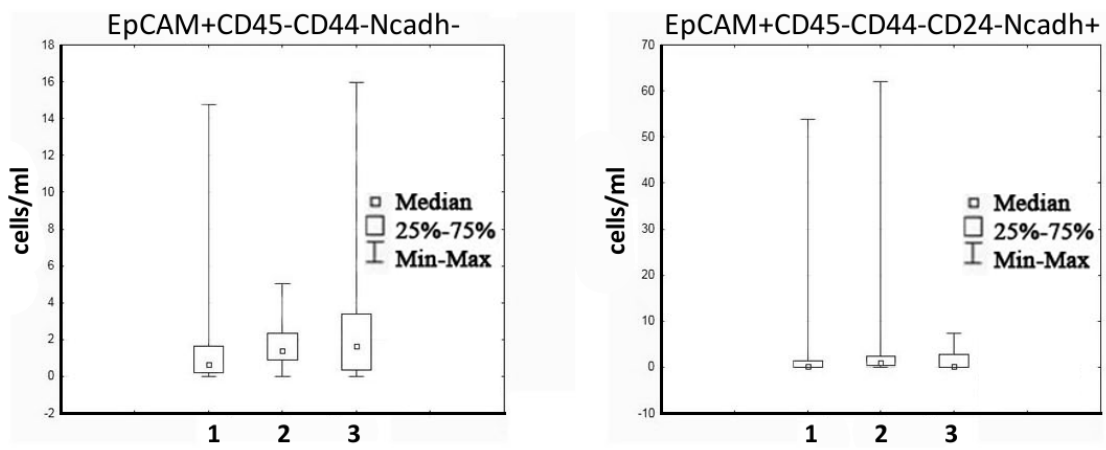

EpCAM+CD45-CD44+CD24-Ncadh-
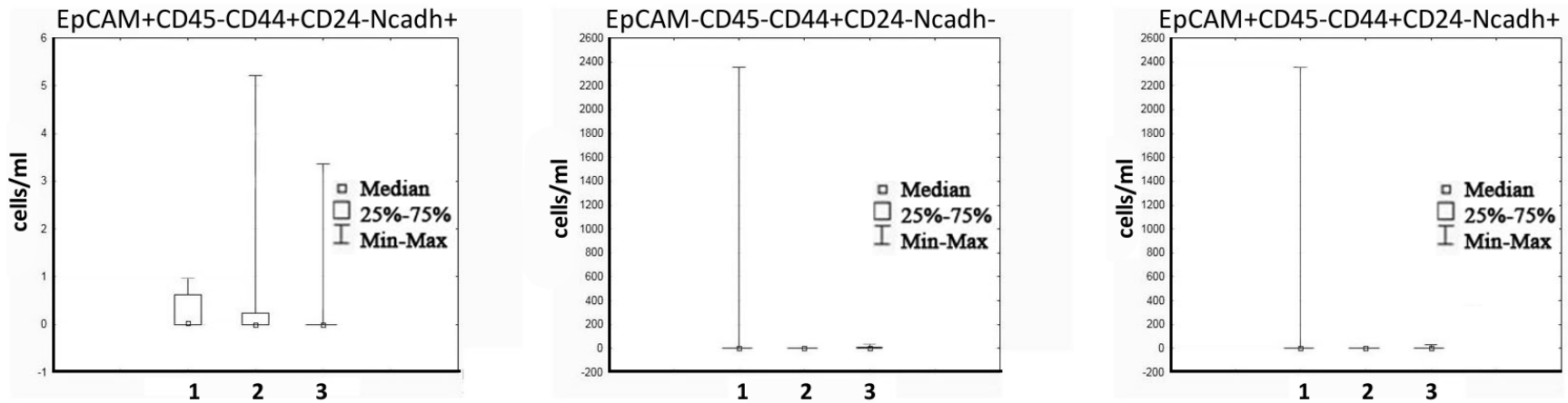

Figure 2. Changes in the level of different populations of circulating tumor cells in the blood of patients with breast cancer 1 - The levels of CTCs (cells / ml) in the blood of breast cancer patients before biopsy; 2 - The levels of CTCs (cells / $\mathrm{ml}$ ) in the blood of breast cancer patients after biopsy; 3 - The levels of CTCs (cells / $\mathrm{ml}$ ) in the blood of breast cancer patients after surgery

are trapped in the circulation or possess sufficient properties to metastasize. Some tumor cells constitute CSCs, while other cells are in the process of the EMT; however, most CTCs are neither stem cells nor in the process of the EMT [5, 18-21]. There are no clear characteristics of these subpopulations that can predict their invasive properties or their ability to metastasize. A meta-analysis of 24 studies (3,701 patients) dedicated to the definition of the prognostic significance of CTCs detected in patients with breast cancer, which included 13 prospective and 11 retrospective studies, showed that a high number of CTCs was associated with a poor response to treatment, shortening the progression-free survival and overall survival of patients [22]. However, the research is not clear as to which CTC subpopulations are associated with poor prognosis. In addition, CTCs have been proposed as biomarkers for the presence of malignant neoplasms [23].

Currently, researchers are actively developing methods for the detection of CTCs. The first clinical test, Cellsearch ${ }^{\otimes}$ (Veridex, Warren, NJ, USA), was tested and approved by the FDA for determining the level of CTCs in patients with cancer. In this test, CTCs are identified as those expressing cytokeratin 8, 18 and 19 among the CD45-positive and CD45-negative nucleated cells $[24,25]$. One of the main limitations of this method is the absence of tumor cell markers for stemness, the EMT and transition states, as well as markers that identify atypical subpopulations of CTCs, as described in detail by Lustberg et al. [25]. In addition, these cytokeratins are not expressed by all tumors, making this test not applicable in patients with squamous cell carcinoma. In this regard, in our study, we used a panel of markers, i.e., EpCAM, CD45, CD44, CD24 and CD325 (N-cadherin), to distinguish CTCs with signs of the EMT and stemness, without signs of stemness or the EMT, and other combinations.

Tumor cells must enter from the surrounding tissue (local invasion) through the basal membrane of the vessel wall (intravasation) to become CTCs. For this process, the tumor cells must acquire the appropriate qualities. There are two variants of tumor cell invasion: collective invasion and the invasion of individual cells. As part of the invasion of individual cells, there are different amebic and mesenchymal types of migration [26].

Tumor invasion is characterized by high expression of E-cadherin and integrins ( $\beta 1$ and $\beta 3$ family) as well as proteases (MMP2 and MMP9). Tumor cells can transition from collective invasion to the invasion of individual cells by two mechanisms: the EMT and collective-amoeboid transitions. The induction of the EMT follows 5 major signaling pathways (TGF $\beta$, Wnt- $\beta$-catenin, BMP, Notch and Hedgehog) with 4 basic stimuli (cytokines, growth factors, hypoxia and extra- 
Table 2. The levels of different populations of CTCs in the blood of breast cancer patients before biopsy, after biopsy and after surgery (Me (Q1-Q3) (cells / $\mathrm{ml}$ ))

\begin{tabular}{|c|c|c|c|c|}
\hline Cell phenotype & The point of the study & $\begin{array}{l}\text { Before biopsy } \\
\qquad \mathrm{N}=22\end{array}$ & $\begin{array}{l}\text { After biopsy } \\
\qquad \mathrm{N}=21\end{array}$ & $\begin{array}{l}\text { After surgery without } \\
\text { NAC } \\
\mathrm{N}=8\end{array}$ \\
\hline $\begin{array}{l}\text { CTCs without signs of the EMT nor } \\
\text { stemness (CTCs - 1) }\end{array}$ & EpCAM+CD45-CD44-CD24-Ncadh- & $\begin{array}{c}0.623 \\
(0.18-1.62)\end{array}$ & $\begin{array}{c}1.405 \\
(0.89-2.34) \\
\mathrm{p}_{1}<0.001\end{array}$ & $\begin{array}{c}2.58 \\
(1.00-10.34) \\
p_{1}=0.247 \\
p_{2}=0.770\end{array}$ \\
\hline $\begin{array}{l}\text { CTCs with signs of the EMT but with- } \\
\text { out signs of stemness (CTCs - 2) }\end{array}$ & $\begin{array}{l}\text { EpCAM+CD45-CD44-CD24- } \\
\text { Ncadh+ }\end{array}$ & $\begin{array}{c}0.094 \\
(0.00-1.29)\end{array}$ & $\begin{array}{c}1.03 \\
(0.29-2.31) \\
\mathrm{p}_{1}=0.222\end{array}$ & $\begin{array}{c}0.64 \\
(0.12-7.46) \\
p_{1}=0.144 \\
p_{2}=0.141\end{array}$ \\
\hline $\begin{array}{l}\text { CTCs with signs of both stemness and } \\
\text { the EMT (CTCs - 3) }\end{array}$ & $\begin{array}{l}\text { EpCAM+CD45-CD44+CD24- } \\
\text { Ncadh+ }\end{array}$ & $\begin{array}{c}0.022 \\
(0.00-0.629)\end{array}$ & $\begin{array}{c}0.00 \\
(0.00-0.246) \\
\mathrm{p}_{1}=0.490\end{array}$ & $\begin{array}{c}0.00 \\
(0.00-0.00) \\
\mathrm{p}_{1}=0.710 \\
\mathrm{p}_{2}=0.170\end{array}$ \\
\hline $\begin{array}{l}\text { CTCs with signs of stemness and with- } \\
\text { out signs of the EMT (CTCs - } 4)\end{array}$ & EpCAM+CD45-CD44+CD24-Ncadh- & $\begin{array}{c}0.058 \\
(0.00-0.45)\end{array}$ & $\begin{array}{c}0.626 \\
(0.104-1.82) \\
\mathrm{p}_{1}=0.009\end{array}$ & $\begin{array}{c}0.43 \\
(0.00-2.24) \\
\mathrm{p}_{1}=0.210 \\
\mathrm{p}_{2}=0.600\end{array}$ \\
\hline $\begin{array}{l}\text { CTCs with signs of both stemness and } \\
\text { the EMT (CTCs - 5) }\end{array}$ & EpCAM-CD45-CD44+CD24-Ncadh- & $\begin{array}{c}0.27 \\
(0.00-4.75)\end{array}$ & $\begin{array}{c}0.10 \\
(0.00-0.92) \\
p_{1}=0.041\end{array}$ & $\begin{array}{c}2.69 \\
(0.83-6.27) \\
p_{1}=0.220 \\
p_{2}=0.138\end{array}$ \\
\hline $\begin{array}{l}\text { CTCs with signs of both stemness and } \\
\text { the EMT (CTCs - } 6 \text { ) }\end{array}$ & EpCAM-CD45-CD44+CD24-Ncadh+ & $\begin{array}{c}0.098 \\
(0.00-0.89)\end{array}$ & $\begin{array}{c}0.22 \\
(0.04-1.59) \\
\mathrm{p}_{1}=0.550\end{array}$ & $\begin{array}{c}0.107 \\
(0.04-2.51) \\
\mathrm{p}_{1}=0.710 \\
\mathrm{p}_{2}=0.720\end{array}$ \\
\hline
\end{tabular}

$\mathrm{p}_{1}=$ significance of differences compared with the same indicator before the biopsy

$\mathrm{p}_{2}=$ significance of differences compared with the same indicator after the biopsy.

cellular matrix components) [27]. The EMT is the result of activation of the transcription factors TWIST1, Snail, Slug and ZEB1/2 and is characterized by high expression of proteases (MMP2 and MMP9) and decreased expression of E-cadherin. During full EMT, tumor cells acquire mesenchymal phenotypes, and they are separated from the tumor mass and move into the mesenchyme. The cell microenvironment involved in the regulation of the EMT includes Th2 lymphocytes, M2 macrophages (TAMs) and fibroblasts (CAFs) [28]. It has been shown that CAFs can promote tumor invasion, thereby inducing the EMT $[29,30]$. It has also been shown that tumor-resident M2-polarized macrophages promote EMT development in pancreatic cancer cells via the TLR4/IL-10 signaling pathway [31]. The mesenchymal type of migration of individual cells dominates the microenvironment with a "dense" matrix due to the characteristic overexpression of FGFR1. As a result of alterations to the activity of certain molecules, cells can migrate and invade in processes termed the amoeboid-mesenchymal and mesenchymal-amoebic transitions [26].

The injury from tumor biopsy is accompanied by inflammation, angiogenesis and reparation. There is hemorrhaging at the site of the tumor where the biopsy was performed, and this tissue damage induces inflammation, which is acute at first but then stimulates productive and reparative regeneration of connective tissue. These processes include angiogenesis and the formation of connective tissue, which are stimulated by cytokine production, lymphocyte elements, macrophages and fibroblasts (myofibroblasts). This spectrum of cytokines is related to the Th2 type of immuno-inflammatory response [28]. Collectively, these processes (damage and regeneration) are responsible for the recruitment of tumor cells, their entrance into the vasculature and the appearance of CTCs in the blood.

In contrast to biopsy, the surgical removal of a tumor, which is also accompanied by trauma, includes reparative processes, and the absence of tumor cells means that there is no source to increase the baseline CTC numbers. We can also assume that the number of distinct populations of CTCs after surgery will depend on the neoadjuvant chemotherapy, the density of blood vessels in the tumor, type of surgery, tumor size and stage of disease. Evaluation and characterization of CTCs have become a major focus of translational cancer research. Presence of CTCs predicts worse clinical outcome in early and metastatic breast cancer. Whether all cells from the primary tumor have potential to disseminate and form subsequent metastasis remains unclear. Several researchers postulated that some CTCs express stem cell-like phenotype; this might lead to chemoresistance and enhanced metastatic 
potential of such cells [32]. It has been proposed that CSCs in primary tumors can metastasize to distant tissues or organs to disseminate and form metastatic colonies via EMT [33, 34]. A recent study has revealed a dynamic in vivo pattern of epithelial-to-mesenchymal transitions in circulating tumor cells and metastases of breast cancer [35]. The CD44+/ CD24- subpopulation in RAS or HER2 overexpressing tumor cells is considered to be the phenotype with increased EMT potential $[36,37]$.

Thus, our results suggest that a small operational trauma contributes to the release of CTCs into the bloodstream, including cells with signs of stemness (EpCAM+CD44+CD45CD24-Ncadh-). These results are interesting from the point of view of studying the mechanisms and factors related to the dissemination of breast cancer cells that may contribute to the future prevention of distant metastases.

Acknowledgements: The study was supported by the Russian Scientific Foundation, grant \# 16-15-10221. We acknowledge support of this work by the Tomsk State University Competitiveness Improvement Program.

\section{References}

[1] SCHATTON T, MURPHY GF, FRANK NY, YAMAURA K, WAAGA-GASSER AM et al. Identification of cells initiating human melanomas. Nature 2008; 451: 345-349. https://doi. org/10.1038/nature06489

[2] DIEHN M, CHO RW, CLARKE MF. Therapeutic implications of the cancer stem cell hypothesis. Semin Radiat Oncol 2009; 19: 78-86. https://doi.org/10.1016/j.semradonc.2008.11.002

[3] DIEHN M, CHO RW, LOBO NA, KALISKY T, DORIE MJ et al. Association of reactive oxygen species levels and radioresistance in cancer stem cells. Nature 2009; 458: 780-783. https://doi.org/10.1038/nature07733

[4] LAGADEC C, VLASHI E, DELLA DONNA L, MENG Y, DEKMEZIAN C, et al. Survival and self-renewing capacity of breast cancer initiating cells during fractionated radiation treatment. Breast Cancer Res 2010; 12: R13. https://doi. org/10.1186/bcr2479

[5] MEGO M, GIORDANO A, DE GIORGI U, MASUDA H, HSU L et al. Circulating tumor cells in newly diagnosed inflammatory breast cancer. Breast Cancer Res 2015; 17: 2. https://doi. org/10.1186/s13058-014-0507-6

[6] PANTEL K, ALIX-PANABIÈRES C, RIETHDORF S. Cancer micrometastases. Nat Rev Clin Oncol 2009; 6: 339-351. https://doi.org/10.1038/nrclinonc.2009.44

[7] FEHM T, SAGALOWSKY A, CLIFFORD E, BEITSCH P, SABOORIAN H et al. Cytogenetic evidence that circulating epithelial cells in patients with carcinoma are malignant. Clinical Cancer Res 2002; 8: 2073-2084.

[8] WRIGHT MH, CALCAGNO AM, SALCIDO CD, CARLSON MD, AMBUDKAR SV et al. Brca1 breast tumors contain distinct CD44+/CD24- and CD133+ cells with cancer stem cell characteristics. Breast Cancer Res 2008; 10: R10. https:// doi.org/10.1186/bcr 1855
[9] THEODOROPOULOS PA, POLIOUDAKI H, AGELAKI S, KALLERGI G, SARIDAKI Z et al. Circulating tumor cellswith a putative stem cell phenotype in peripheral blood of patients with breast cancer. Cancer Lett 2010; 288: 99-106. https://doi. org/10.1016/j.canlet.2009.06.027

[10] REUBEN JM, LEE BN, GAO H, COHEN EN, MEGO M et al. Primary breast cancer patients with high risk clinicopathologic features have high percentages of bonemarrow epithelial cells with ALDH activity and CD44+CD24lo cancer stem cell phenotype. Eur J Cancer 2011; 47: 1527-1536. https://doi. org/10.1016/j.ejca.2011.01.011

[11] ARMSTRONG AJ, MARENGO MS, OLTEAN S, KEMENY G, BITTING RL et al. Circulating tumor cells from patients with advanced prostate and breast cancer display both epithelial and mesenchymal markers. Mol Cancer Res 2011; 9: 997-1007. https://doi.org/10.1158/1541-7786.MCR-10-0490

[12] YU M, BARDIA A, WITTNER BS, STOTT SL, SMAS ME et al. Circulating breast tumor cells exhibit dynamic changes in epithelial and mesenchymal composition. Science 2013; 339: 580-584. https://doi.org/10.1126/science.1228522

[13] BUTLER TP, GULLINO PM. Quantitation of cell shedding into efferent blood of mammary adenocarcinoma. Cancer Res 1975; 35: 512-516.

[14] FIDLER IJ, YANO S, ZHANG RD, FUJIMAKI T, BUCANA CD. The seed and soil hypothesis: vascularisation and brain metastases. Lancet Oncol 2002; 3: 53-57. https://doi. org/10.1016/S1470-2045(01)00622-2

[15] ZHE X, CHER ML, BONFIL RD. Circulating tumor cells: finding the needle in the haystack. Am J Cancer Res 2011; 1: $740-751$.

[16] DEMICHELI R, ABBATTISTA A, MICELI R, VALAGUSSA P, BONADONNA G. Time distribution of the recurrence risk for breast cancer patients undergoing mastectomy: further support about the concept of tumor dormancy. Breast Cancer Res Treat 1996; 41: 177-185. https://doi.org/10.1007/BF01807163

[17] UHR JW, PANTEL K. Controversies in clinical cancer dormancy. Proc Natl Acad Sci U S A 2011; 108: 12396-12400. https://doi.org/10.1073/pnas.1106613108

[18] KRISHNAMURTHY S. The emerging role of circulating tumor cells in breast cancer. Cancer Cytopathol 2012; 120: 161-166. https://doi.org/10.1002/cncy.20207

[19] GIORDANO A, GAO H, ANFOSSI S, COHEN E, MEGO $\mathrm{M}$ et al. Epithelial-mesenchymal transition and stem cell markers in patients with HER2-positive metastatic breast cancer. Mol Cancer Ther 2012; 11: 2526-2534. https://doi. org/10.1158/1535-7163.MCT-12-0460

[20] MARKIEWICZ A, WEŁNICKA-JAŚKIEWICZ M, SEROCZYNSKA B, SKOKOWSKI J, MAJEWSKA H et al. Epithelial-mesenchymal transition markers in lymph node metastases and primary breast tumors - relation to dissemination and proliferation. Am J Transl Res 2014; 6: 793-808.

[21] KAIGORODOVA E, TARABANOVSKAYA N, SIMOLINA E, PERELMUTER V, STAKHEEVA $M$ et al. Circulating tumor cells and bone marrow progenitor cells in the blood of breast cancer patients in the dynamics of neoadjuvant chemotherapy. EJC Suppl 2015; 13: 22-23. https://doi.org/10.1016/j.ejcsup.2015.08.039 
[22] LV QB, FU X, JIN HM, XU HC, HUANG ZY et al. The relationship between weight change and risk of hip fracture: meta-analysis of prospective studies. Sci Rep 2015; 5: 16030. https://doi.org/10.1038/srep16030

[23] LIANIDOU ES, MARKOU A, STRATI A. The role of CTCs as tumor biomarkers. Adv Exp Med Biol 2015; 867: 341-367. https://doi.org/10.1007/978-94-017-7215-0 21

[24] HOFMAN VJ, ILIE M, HOFMAN PM. Detection and characterization of circulating tumor cells in lung cancer: why and how? Cancer Cytopathol 2016; 124: 380-387. https://doi. org/10.1002/cncy.21651

[25] LUSTBERG MB, BALASUBRAMANIAN P, MILLER B, GARCIA-VILLA A, DEIGHAN C et al. Heterogeneous atypical cell populations are present in blood of metastatic breast cancer patients. Breast Cancer Res 2014; 16: R23,. doi 10.1186/ bcr3622. https://doi.org/10.1186/bcr3622

[26] KRAKHMAL NV, ZAVYALOVA MV, DENISOV EV, VTORUSHIN SV, PERELMUTER VM. Cancer invasion: patterns and mechanisms. Acta Naturae 2015; 7: 17-28.

[27] GONZALEZ DM, MEDICI D. Signaling mechanisms of the epithelial-mesenchymal transition. Sci Signal 2014; 7: re8. https://doi.org/10.1126/scisignal.2005189

[28] YEUNG OW, LO CM, LING CC, QI X, GENG W et al. Alternatively activated (M2) macrophages promote tumour growth and invasiveness in hepatocellular carcinoma. J Hepatol 2015; 62: 607-616. https://doi.org/10.1016/j.jhep.2014.10.029

[29] BHOWMICK NA, NEILSON EG, MOSES HL. Stromal fibroblasts in cancer initiation and progression. Nature 2004; 432: 332-337. https://doi.org/10.1038/nature03096

[30] KALLURI R, ZEISBERG M. Fibroblasts in cancer. Nat Rev Cancer 2006; 6: 392-401. https://doi.org/10.1038/nrc1877
[31] LIU CY, XU JY, SHI XY, HUANG W, RUAN TY et al. M2-polarized tumor-associated macrophages promoted epithelial-mesenchymal transition in pancreatic cancer cells, partially through TLR4/IL-10 signaling pathway. Lab Invest 2013; 93: 844-854. https://doi.org/10.1038/labinvest.2013.69

[32] KRAWCZYKN, MEIER-STIEGEN F, BANYS M, NEUBAUER $\mathrm{H}, \mathrm{RUCKHAEBERLE} \mathrm{E} \mathrm{et} \mathrm{al.} \mathrm{Expression} \mathrm{of} \mathrm{stem} \mathrm{cell} \mathrm{and}$ epithelial-mesenchymal transition markers in circulating tumor cells of breast cancer patients. Biomed Res Int 2014; 2014: 415721. https://doi.org/10.1155/2014/415721

[33] GUPTA PB, CHAFFER CL, WEINBERG RA. Cancer stem cells: mirage or reality? Nat Med 2009; 15: 1010-1012. https:// doi.org/10.1038/nm0909-1010

[34] GENG SQ, ALEXANDROU AT, LI JJ. Breast cancer stem cells: Multiple capacities in tumor metastasis. Cancer Lett 2014; 349: 1-7. https://doi.org/10.1016/j.canlet.2014.03.036

[35] BONNOMET A, SYNE L, BRYSSE A, FEYEREISEN E, THOMPSON EW et al. A dynamic in vivo model of epithelialto-mesenchymal transitions in circulating tumor cells and metastases of breast cancer. Oncogene 2012; 31: 3741-3753. https://doi.org/10.1038/onc.2011.540

[36] BHAT-NAKSHATRI P, GOSWAMI CP, BADVE S, SLEDGE GW JR, NAKSHATRI H. Identification of FDAapproved drugs targeting breast cancer stem cells along with biomarkers of sensitivity. Sci Rep 2013; 3: 2530. https://doi.org/10.1038/ $\underline{\text { srep02530 }}$

[37] WANG KH, KAO AP, LIN TC, CHANG CC, KUO TC. Promotion of epithelial-mesenchymal transition and tumor growth by 17beta-estradiol in an ER(+)/HER2(+) cell line derived from human breast epithelial stem cells. Biotechnol Appl Biochem 2012; 59: 262-267. https://doi.org/10.1002/bab.1022 